\title{
Load-bearing capacity of the steel-to-timber connections in fire temperature
}

\author{
Tomasz Domański ${ }^{1, *}$, and Kamil Kmiecik ${ }^{1}$ \\ ${ }^{1}$ Cracow University of Technology, The Faculty of Engineering, ul.Warszawska 24, Cracow 31-155, Poland
}

\begin{abstract}
Connections are usually the weakest parts in most structures, especially in fire conditions. The load-bearing capacity of timber structures is often limited by the resistance of steel connection between timber structural members. The temperature distribution in the cross-section as well as the influence of steel fasteners on the charring of the timber members is necessary to predict the fire resistance of the connection. This paper presents a summary of results from numerical studies on the fire behaviour of the steel connections between timber structural members. To make the three-dimensional thermal models of the joints, the FE (finite element) programme SAFIR was used. Then, the finite element models of the connections were used to analyse the temperature distribution inside cross-sections under standard ISO-fire exposure. The failure modes from the literature were used to predict the load-bearing capacity of the steel connections at elevated temperatures. The reduction of the cross-section caused by charring, the reduction of embedment strength and the reduction of steel strength at fire conditions were taken into account in the calculations.
\end{abstract}

\section{Introduction}

Steel-to-timber dowelled connections are made of cylindrical steel dowels. This type of joint is used to carry loads perpendicular to the dowel axis. Multiple shear connections with slotted-in steel plates have a high load-bearing capacity at ambient temperature. In normal conditions, a ductile failure mode were observed as main failure mode. The load-bearing capacity of the joints depends on the embedment strength of the timber elements and the yield moment of the steel fasteners. Predicting the bearing capacity of a steel connection between timber structural members in fire temperature is challenging and complex. It depends on several parameters like the geometry of the connection, steel fastener diameter, different thermal properties of wood and steel, thermal interaction between timber and steel members. To estimate load-bearing capacity of the joint at elevated temperatures, we must know the temperature distribution in the cross-section and the influence of steel elements on the charring of the timber members.

EN 1995-1-2 [1] proposes two methods for calculating the fire resistance of timber connections exposed to fire: reduced load method and application of simplified rules. The first method is valid for symmetrical three-member connections, loaded laterally under ISO fire exposure [2]. There are no design models for multiple shear steel-to-timber connections with two or more slotted-in-plates.

This paper presents the results of numerical analyses on the fire behaviour of the steel connections between timber members. Particular emphasis was placed on the influence of the steel members on the temperature distribution in the cross-section.

\section{Thermal analysis}

\subsection{Thermal properties of materials}

To model heat transfer in the joints, proper input data for timber and steel at high temperatures are required. For steel, the thermal properties at elevated temperatures are well documented in the literature.

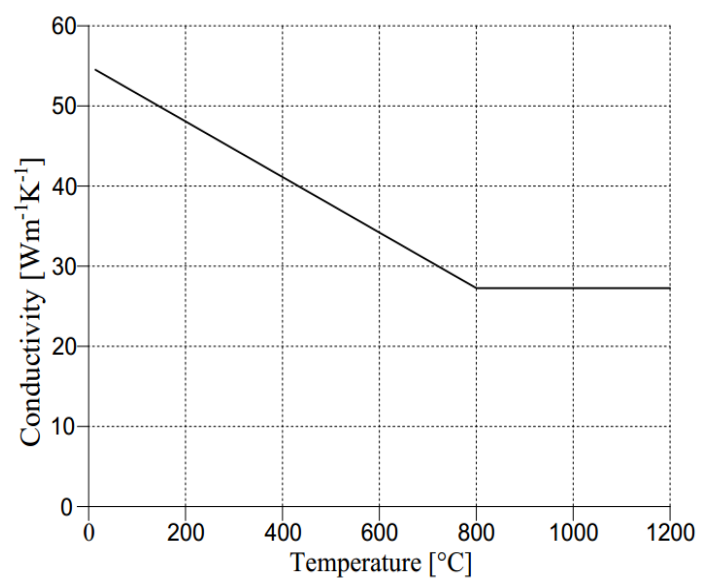

Fig. 1. Thermal conductivity of carbon steel as a function of the temperature, based on EN 1993-1-2 [3].

The density of steel remaining constant with temperatures. The thermal conductivity and specific heat 
versus temperature were taken from EN 1993-1-2 [3]. Figure 1 show the thermal conductivity of steel according to temperature.

The thermal properties of wood are varied considerably with temperature. The thermal conductivity values of the char layer increase at temperatures exceeding $500{ }^{\circ} \mathrm{C}$, because of shrinkage of the char layer and the effect of cracks. A peak at about $100{ }^{\circ} \mathrm{C}$ represents the heat required to evaporate the moisture in wood. Timber turns to char at about $300{ }^{\circ} \mathrm{C}$. At elevated temperatures, the density is not constant. It drops to about $90 \%$ in $100{ }^{\circ} \mathrm{C}$ and to about $20 \%$ when the temperature exceeds $300{ }^{\circ} \mathrm{C}$.

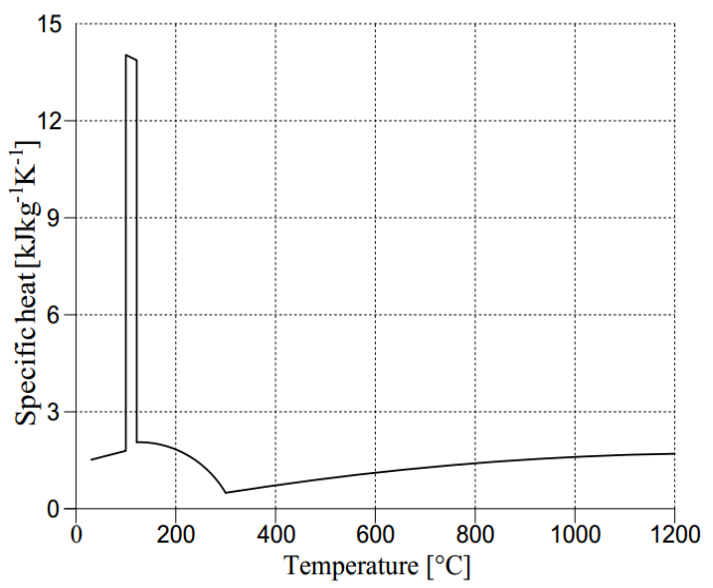

Fig. 2. Thermal-specific heat relationship for wood and the charcoal, based on EN 1995-1-2 [1].

\subsection{Theoretical background of heat transfer}

Three types of heat transfer processes should be considered in modelling the steel connection between timber structural members: convective and radiative heat transfer from fire to element boundary, heat exchange between steel and wood members and heat conduction in the element. The three-dimensional heat transfer element with linear interpolation has been used to model the transient heat conduction within the connection members. The governing partial differential equation should be defined as follows:

$$
\frac{\partial}{\partial x}\left(\lambda_{x} \frac{\partial T}{\partial x}\right)+\frac{\partial}{\partial y}\left(\lambda_{y} \frac{\partial T}{\partial y}\right)+\frac{\partial}{\partial z}\left(\lambda_{z} \frac{\partial T}{\partial z}\right)+\dot{Q}=\rho c \frac{\partial T}{\partial t}(1)
$$

where $T(\mathrm{~K})$ is temperature, $\lambda_{x, y, z}(\mathrm{~W} / \mathrm{mK})$ are thermal conductivities in $x, y, z$ directions, $Q\left(\mathrm{~W} / \mathrm{m}^{3}\right)$ is internally generated heat, $\rho\left(\mathrm{kg} / \mathrm{m}^{3}\right)$ is density, $c(\mathrm{~J} / \mathrm{kgK})$ is specific heat, and $t(\mathrm{~s})$ is time.

Thermal actions are given by the heat flux to the surface of the member. The net heat flux in fire conditions, should consist of heat transfer by radiation and convection. The equation is given by:

$$
q^{\prime \prime}=h_{c}\left(T_{f}-T_{s}\right)+\Phi \varepsilon_{e f f} \sigma\left(T_{f}^{4}-T_{s}^{4}\right)
$$

where $h_{c}\left(\mathrm{~W} / \mathrm{m}^{2} \mathrm{~K}\right)$ is the convection coefficient, $\Phi$ is the configuration factor, $\sigma$ is the Stefan-Boltzmann constant, $\varepsilon_{\text {eff }}$ is the effective emissivity, $T_{s}(\mathrm{~K})$ is the surface of the member temperature and $T_{f}(\mathrm{~K})$ is the fire temperature. The convection coefficient $h_{c}$ for the standard fire is 25 $\mathrm{W} / \mathrm{m}^{2} \mathrm{~K}[4]$. In the standard fire test, the configuration factor $\Phi$ can be taken as 1.0. The efficient emissivity $\varepsilon_{\text {eff }}$ should be defined as:

$$
\varepsilon_{e f f}=\frac{\varepsilon_{f} \varepsilon_{s}}{\varepsilon_{f}+\varepsilon_{s}-\varepsilon_{f} \varepsilon_{s}}
$$

where $\varepsilon_{f}$ is emissivity of the furnace, $\varepsilon_{s}$ is the surface emissivity.

For the standard ISO 834 fire curve, the fire temperature $T_{f}\left({ }^{\circ} \mathrm{C}\right)$ at time is given by [5]:

$$
T_{f}=20+345 \times \log _{10}(8 t+1)
$$

The heat transfer between members in FE model should be defined with proper contact properties. Gaps between steel elements and wood members are assumed to be sufficiently narrow. Heat transfer between members is restricted to be radiation and conduction through air:

$$
q_{G}^{\prime \prime}=k_{\text {air }} \frac{\Delta T}{L}+4 \sigma \bar{T}^{3} \Delta T /\left(\frac{1}{\varepsilon_{H}}+\frac{1}{\varepsilon_{C}}-1\right)
$$

where $\Delta T=T_{H}-T_{C}, k_{\text {air }}$ is the thermal conductivity of air, $L$ is the thickness of air layer, $\varepsilon_{C}$ is the cold interface emissivity and $\varepsilon_{H}$ is the hot interface emissivity. The thermal conductivity of air is given as [6]:

$$
k_{\text {air }}=0.024+7.05 \times 10^{-5} T_{\text {air }}-1.59 \times 10^{-8} T_{\text {air }}^{2}
$$

where $T_{\text {air }}$ is the air temperature $\left({ }^{\circ} \mathrm{C}\right)$.

\subsection{Validation of the Finite Element Model}

To make a three-dimensional thermal model of the connection, the finite element software SAFIR [7] was used (Fig. 3). Before using the model to simulate heat transfer, it is important to validate the timber properties at elevated temperatures used in this investigation.

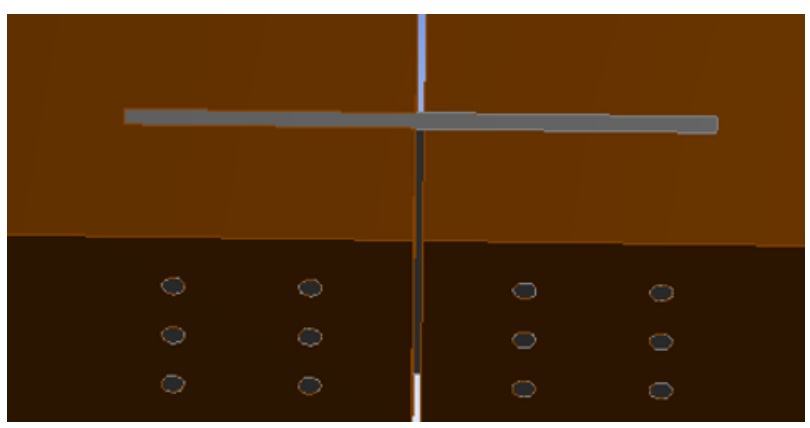

Fig. 3. Model of the connection.

The temperature-dependent properties were defined in SAFIR [7]. To validate this software, the results of Konig's fire tests [8] were used. In Konig's tests, the timber samples were spruce with density of about 420 
$\mathrm{kg} / \mathrm{m}^{3}$ and $12 \%$ moisture content. Timber members were exposed to the - ISO 834 fire curve. Temperatures were measured in a depth of $6,18,30$ and $42 \mathrm{~mm}$ from the exposed surface. The comparison of modelling results with the results of Konig's fire tests is shown in Figure 4. The Finite Element method are in good agreement with results from the fire tests.

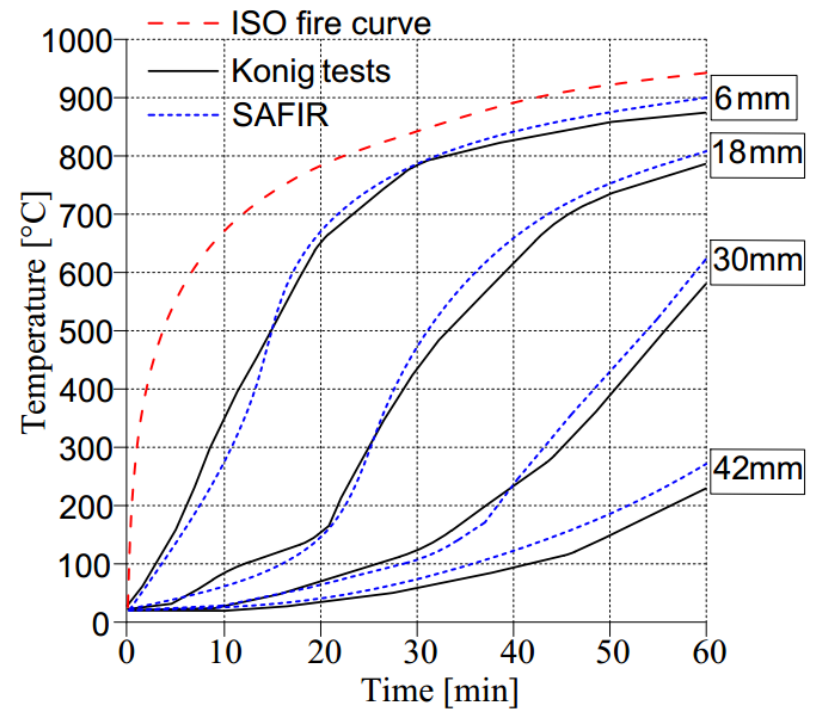

Fig. 4. Temperature as a function of time at different timber depths under ISO fire.

\subsection{Thermal FE - simulations}

The purpose of modelling the connections using the finite element method was to determine the influence of steel members (plates and dowels) in timber joints on the temperature distribution during fire exposure. Figure 5 shows the geometry of the modelled connections. The joints consist of timber member $(200 \times 240 \mathrm{~mm})$, one, two or three slotted-in-steel plates with a thickness of 5 $\mathrm{mm}$ each and two rows of 3 steel dowels (diameter 10 mm each).

The 3-dimensional Finite Element model of the joints were made. The fire load according to ISO 834 fire curve [2] was applied on four sides of the connections. In modelling joints with different members and materials, the most important issue is to simulate the contact conditions correctly. In the analysed connection are three contact situations between various surfaces:

- The timber and the steel plates

- The steel plates and the steel dowels

- The timber and the steel dowels

Figures $6 \mathrm{a}, \mathrm{b}, \mathrm{c}$ show the temperature distribution of the timber joints with steel members after 15, 30 and 45 minutes of fire exposure. The temperature in steel elements increases almost linearly with time. At the same depth from the exposed surface, the temperatures inside the timber elements are much lower than the temperatures inside of the steel fasteners. This is due to the higher conductivity of steel [9]. On the surface, the temperature of the steel members is lower than the temperature of the wood.
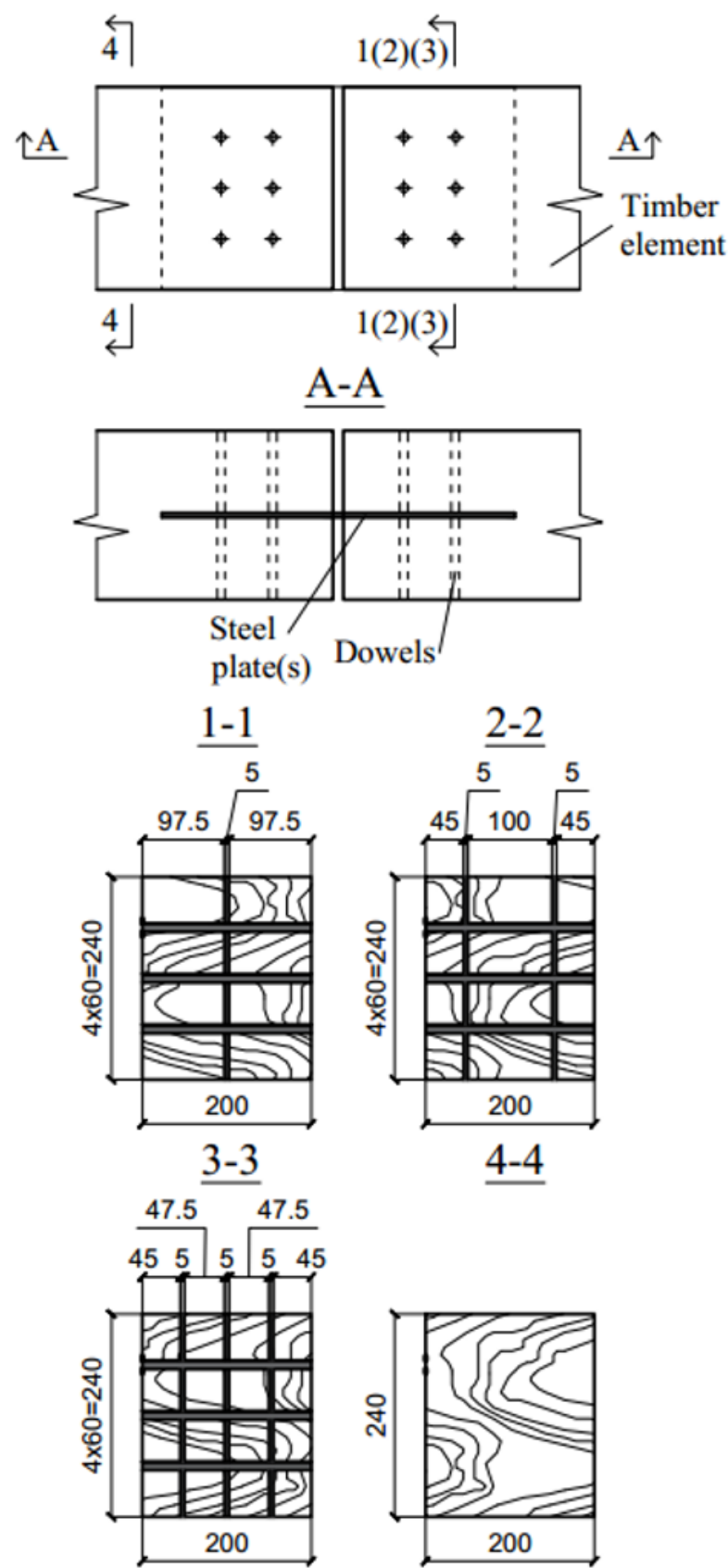

Fig. 5. Geometry of the modelled connections with various numbers of slotted-in plates

Figure $6 \mathrm{~d}$ shows the temperature distribution of the wood members without steel elements. The temperature gradient for the cross-section without steel fasteners is the same on each external surface. In the middle of the timber member, room temperature is still present. 
a)

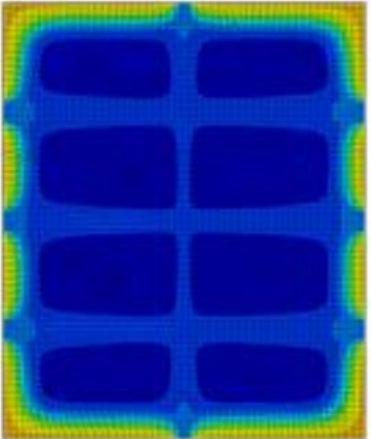

b)

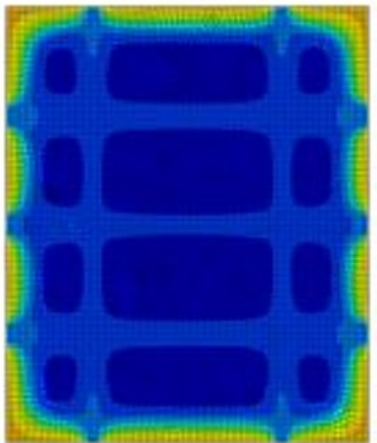

c)

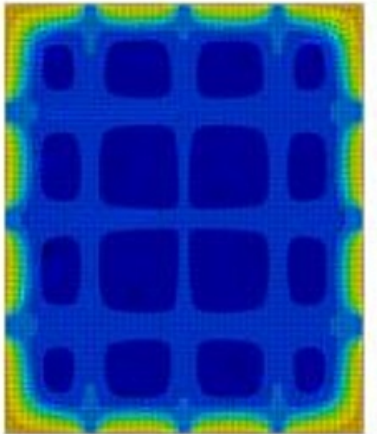

d)

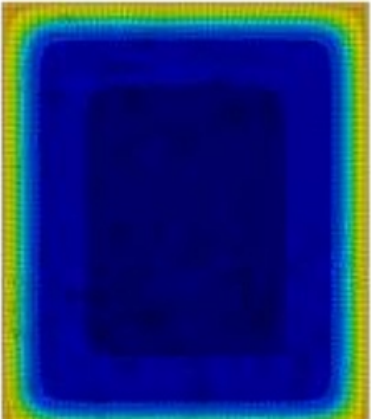

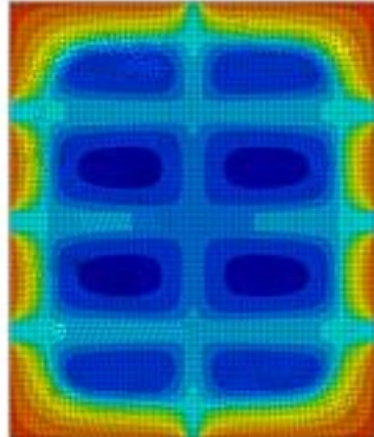
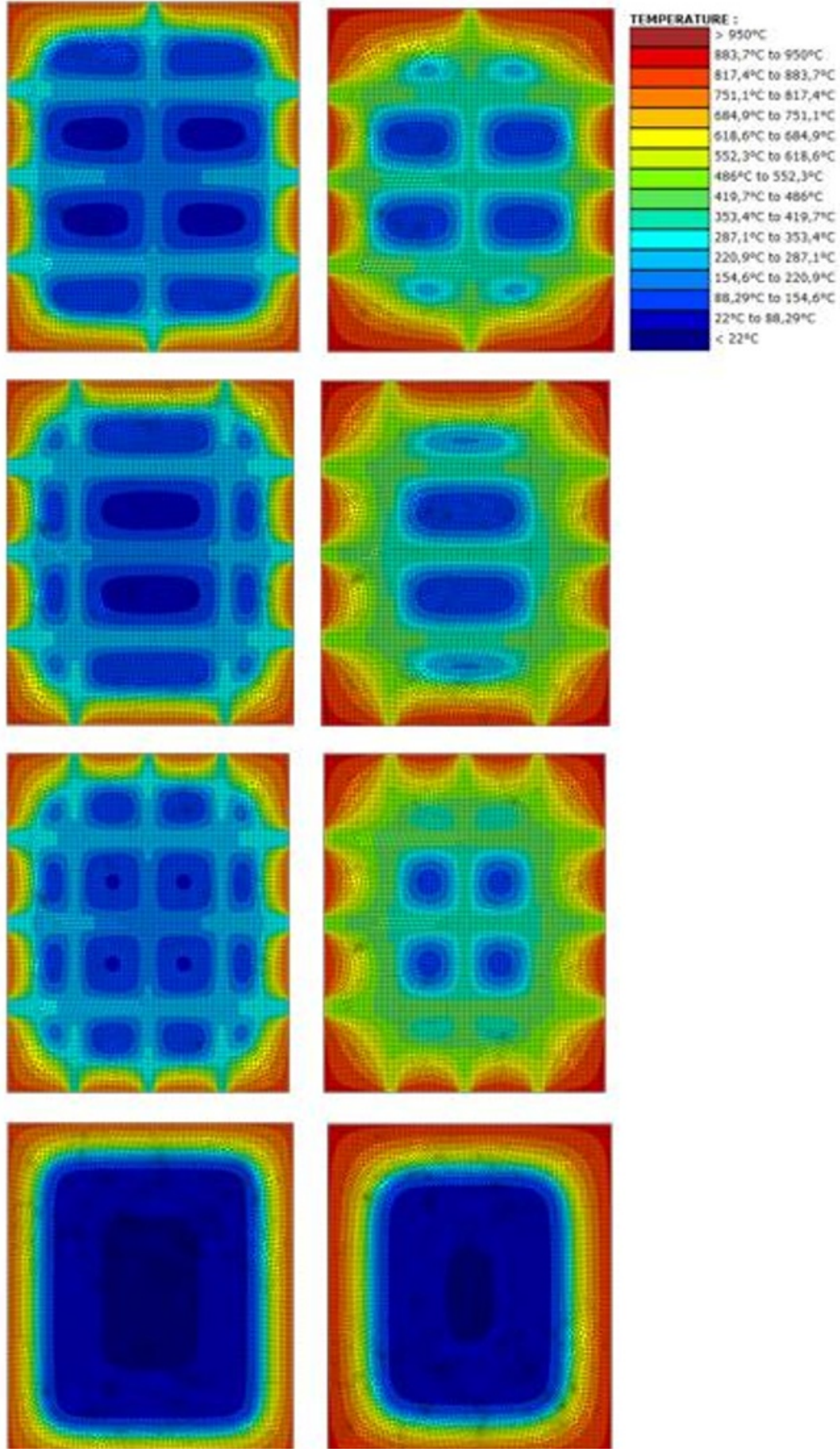

Fig. 6. Temperature distribution in timber members after 15,30 and 45 min (respectively) under ISO-fire exposure on four sides: a) cross-section 1-1 (with one slotted-in plate) b) cross-section 2-2 (with two slotted-in plates), c) cross-section 3-3 (with three slotted-in plates), cross-section 4-4 (without steel members)

\section{Fire design methods}

\subsection{Charring of the cross-section}

Wood is a combustible material. Under fire exposure, timber leads to a process of thermal degradation pyrolysis. It causes chemical and physical changes (formation of char). This phenomenon is accompanied by a loss in mass. In timber members, charring occurs in all fire exposed surfaces. It takes the form of a layer which increases with the progression of fire, reducing the cross-sectional dimensions of the timber. According to EN 1995-1-2 [1] and other authors [10], the location of the charred layer coincides with the $300{ }^{\circ} \mathrm{C}$ isotherm. This layer cannot carry any structural loads, but is a thermal insulation for the remaining uncharred residual cross-section [11]. In calculations the load-bearing capacity of a steel connections between timber structural members exposed to fire, the loss in cross-section as well 
as the reduction in stiffness and strength due to high temperature should be taken into account. The charring rate is constant with time for unprotected timber surfaces exposed to fire [12]. EN 1995-1-2 provides the onedimensional charring rate $\beta_{0}=0.65 \mathrm{~mm} / \mathrm{min}$ for softwood, verified by other authors [10].

\subsection{Design methods for timber members exposed to fire}

During fire exposure, the cross-section and the strength and stiffness of the timber close to the heated surface are reduced. With increasing temperature, the stiffness and strength of timber significantly reduces [13]. The temperature-dependent reduction in stiffness and strength should be taken into account. EN 1995-1-2 [1] provides two simplified methods: the Reduced crosssection method and the Reduced properties method. The first approach takes into account reduction of the strength and stiffness near the charred layer by adding the zero strength layer $\left(k_{0} \cdot d_{0}\right)$ to the charred layer $d_{\text {char,n }}$ (Fig. 7). It is assumed that in the first 20 minutes of fire exposure, the zero strength layer is build up linearly. This method allows to use the properties of strength and stiffness for the ambient temperature for the remaining effective cross-section. For the effective cross-section, the temperature-dependent factor is taken as $k_{\text {mod,fi }}=1.0$. The Reduced properties method provides the temperature-dependent reduction factor $k_{\text {mod,fi. }}$ This factor considers the influence of the temperature reducing the timber strength and stiffness properties of the remaining cross-section.

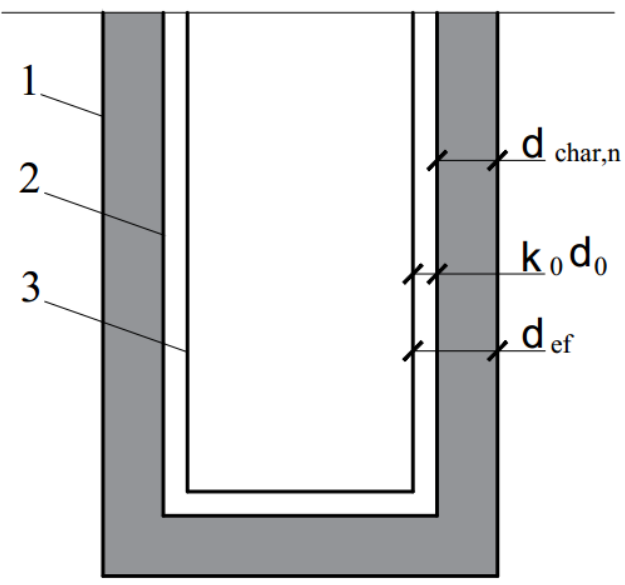

Fig. 7. Definition of residual cross-section and effective crosssection based on [1]

\subsection{Design methods for timber connections according to EN 1995-1-2 [1]}

EN 1995-1-2 provides only some issues of connections design in fire conditions. Design rules apply for symmetrical three-member connections with various types of fasteners (bolts, nails, dowels, etc.) exposed to the ISO standard fire curve. These concern to laterally loaded joints. The maximum fire resistance time is 60 min. The design can be performed by two methods: the reduced load method or application of simplified rules.

According to the first approach, the load-bearing capacity of the connection exposed to fire is achieved by reducing the room temperature capacity via a conversion factor $\eta$. The conversion factor incorporates a dimensionless parameter $k$ depending on the joint type, and the fire resistance of the unprotected connection $t_{\mathrm{d} . \mathrm{fi}}$ (min).

According to the application of simplified rules, the fire resistance of unprotected connections with dowels is assumed to be $20 \mathrm{~min}$. For joints with other connector types, the fire resistance is determined to be $15 \mathrm{~min}$. Fire resistance periods, greater than those above, can be achieved by increasing width and thickness of the side members, as well as by increasing the edge distance.

\section{Fire behaviour of a steel connection between timber structural members}

\subsection{Fire tests}

Erchinger $[10,14]$ performed a series of fire resistance tests on steel-to-timber dowelled connections. The tests consisted of 18 fire tests under standard ISO-fire exposure and 25 tests conducted at ambient temperature. The cross-section of timber members was $200 \mathrm{~mm}$ x 200 $\mathrm{mm}$ with steel dowels and two or three slotted-in steel plates. The samples consisted of glued laminated timber grade GL24h. The mean moisture content was $10 \%$, the density between 390 and $495 \mathrm{~kg} / \mathrm{m}^{3}$. The diameter of the dowels were 6.3 or $12 \mathrm{~mm}$. The tensile strength of the steel fasteners were $598 \mathrm{~N} / \mathrm{mm}^{2}$ for diameter 6.3 and 636 $\mathrm{N} / \mathrm{mm}^{2}$ for diameter 12 . The configuration and number of steel fasteners were varied. The thickness of the steel plates was $5 \mathrm{~mm}$. Failure mode of steel-to-timber connection after fire test is shown on Fig. 8.
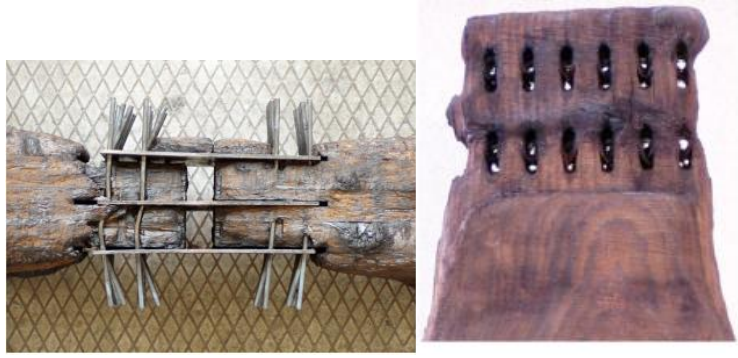

Fig. 8. Failure mode of steel-to-timber connection after fire test [14]

\subsection{Failure modes}

Steel-to-timber dowelled connections loaded in tension can fail in different modes: bearing failure, net tension failure, splitting of wood, shear-out failure and group shear-out failure. The failure modes depends on joint types, configuration of fasteners and geometry of the connection. 
The wood embedment failure in the contact area, with steel yield of fasteners causes of the first failure mode. Other failure modes are brittle. Mostly, failure is composed of different modes.

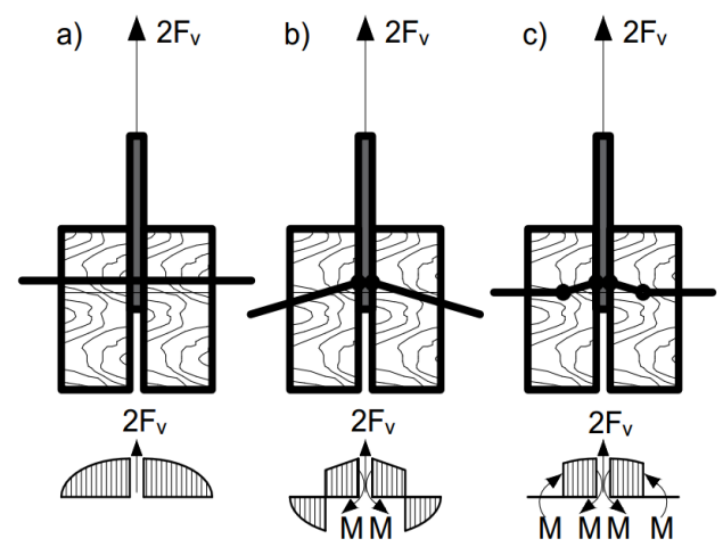

Fig. 9. Failure models of steel-to-timber connections in fire: a) Mode I, b) Mode II, c) Mode III

In fire tests for steel-to-timber joints, first two failure modes were observed as main failure modes: elongation of fastener holes due to timber crushing and deformation of fasteners $[15,16]$. It is caused by charring of timber elements and the fast temperature increasing in steel members. Destruction by the third failure mode can occur when the wood side members are very thick. EN 1995-1-1 [12] gives simplified formulas:

$$
\begin{gathered}
F_{v, R k, I}=f_{h, 1, k} t_{1} d \\
F_{v, R k, I I}=f_{h, 1, k} t_{1} d\left[\sqrt{2+\frac{4 M_{y, R k}}{f_{h, 1, k} d t_{1}^{2}}-1}\right]+\frac{F_{a x, R k}}{4} \\
F_{v, R k, I I I}=2,3 \sqrt{M_{y, R k} f_{h, 1, k} d}+\frac{F_{a x, R k}}{4} \\
F_{v, R k}=\min \left(F_{v, R k, I}, F_{v, R k, I I}, F_{v, R k, I I I}\right)
\end{gathered}
$$

Where $F_{v, R k, i}$ is the load-bearing capacity per shear plane per fastener for $i$ failure mode $(\mathrm{kN}), f_{h, 1, k}$ is the embedment strength in timber member $(\mathrm{MPa}), t_{l}$ is the smaller of the thickness of the timber side member $(\mathrm{mm}), d$ is the fastener diameter $(\mathrm{mm}), M_{y, R k}$ is the fastener yield moment $(\mathrm{kNm})$, and $F_{a x, R k}$ is the withdrawal capacity of the fastener $(\mathrm{kN})$.

\subsection{Load-bearing capacity of the connections in fire conditions}

Steel-to-timber connections have to fulfil the requirements and design rules of Eurocode 5. The yield strength, the diameter and the embedment strength of the fasteners are the main functions used in strength equations. In fire conditions, the wood section is reduced due to charring. During fire exposure, the steel fasteners reduce strength. The yield strength at elevated temperatures is adopted from EN 1993-1-2 [1].
Table 1. Load-bearing capacity per fastener in fire conditions.

\begin{tabular}{|c|c|c|c|c|}
\hline \multirow{2}{*}{$\begin{array}{c}\text { Duration } \\
\text { of fire } \\
\text { [min] }\end{array}$} & \multicolumn{2}{|c|}{$\begin{array}{c}\text { Load-bearing capacity per } \\
\text { fastener for the failure model } \\
\text { [kN] }\end{array}$} & \multirow{2}{*}{$\begin{array}{c}\text { F cross-sk } \\
\text { [kN] }\end{array}$} \\
\cline { 2 - 4 } & Modection I-1) & Mode II & Mode III & \\
\hline 0 & 50,4 & 21,5 & 10,8 & 10,8 \\
15 & 41,3 & 17,8 & 9,9 & 9,9 \\
30 & 31,1 & 13,5 & 8,7 & 8,7 \\
45 & 20,6 & 9,4 & 7,9 & 7,9 \\
60 & 10,3 & 5,6 & 6,9 & 5,6 \\
\hline
\end{tabular}

Table 1 contains load-bearing capacity per fastener for the failure modes at time intervals 15 min under ISOfire exposure. As expected, for estimating the loadbearing capacity of the steel-to-wood joint under fire exposure, the first two are the main failure modes.

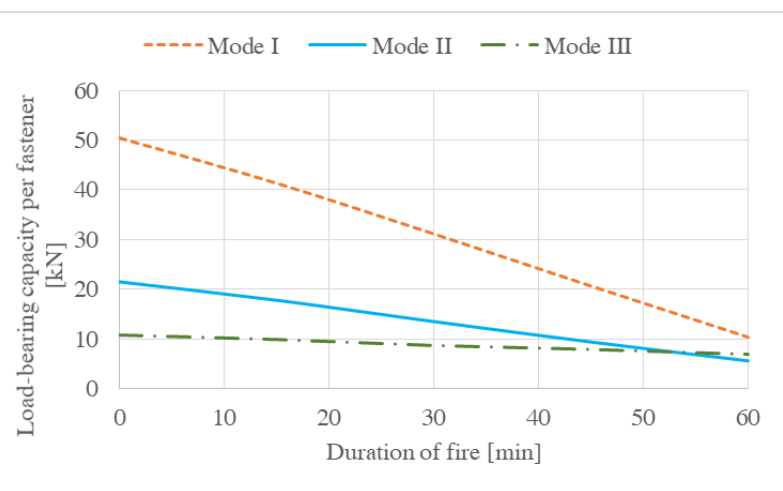

Fig. 10. Load-bearing capacity for failure modes in fire conditions (cross-section 1-1).

The temperature fields in joints with two or three slotted-in plates are higher than with one steel plate. For this reason, the load-bearing capacity for connections with two or three plates is lower than with only one slotted-in plate. Authors [10] proposes a design model for calculating the load-bearing capacity for joints with more than one steel plate. According this model, the load-bearing capacity of the connection fulfil the requirements of fire resistance of 60 minutes.

\section{Conclusions}

The load-carrying capacity of the timber structures is often equivalent with the resistance of the connections. Therefore, knowledge of the fire behaviour of connections is important for effective design. The fire resistance of the multiple shear steel-to-timber connections depends on the temperature distribution in the cross-section and the charring of the wood elements.

The steel members have a huge influence on the temperature fields inside the cross-section. To determine the temperature distribution in the connections, thermal analysis using FE model can be useful. The finite element model can provide good predictions of the 
inside temperature within timber connections with steel members.

\section{References}

1. EN 1995 1-2 Eurocode 5: Design of timber structures, Part 1-2: structural fire design, CEN, Brussels, Belgium, (2004)

2. ISO 834 Fire resistance tests-elements of building construction, Part 1: general requirements, International Organization for Standardization, Switzerland, (1999)

3. EN 1993-1-2 Eurocode 3: Design of steel structures, Part 1-2: General rules - Structural fire design, CEN, Brussels, Belgium, (2005)

4. EN 1991 1-2 Eurocode 1: actions on structures, Part 1-2: General actions - actions on structures exposed to fire, CEN, Brussels, Belgium, (2003)

5. P. Racher, K. Laplanche, D. Dhima, A. Bouchair, Thermo-mechanical analysis of the fire performance of dowelled timber connection, Engineering Structures, 32, 1148-1157 (2010)

6. M. Audebert, D. Dhima, M. Taazount, A. Bouchair, Numerical investigations on the thermo-mechanical behavior of steel-to-timber joints exposed to fire, Engineering Structures, 33, 3257-3268 (2011)

7. J.M. Franssen, T. Gernay, Modeling structures in fire with SAFIR: theoretical background and capabilities, Journal of Structural Engineering, 8, 300-323 (2017)

8. J. Konig, L.Wallei, One-dimensional charring of timber exposed to standard and parametric fires in initially unprotected and post-protection fire situations. Rapport I 9908029, Swedish Institute for Wood Technology Research, Stockholm, Sweden, (1999)

9. V.D. Thi, M. Khelifa, M. Oudjene, M. El Ganaoui, Y. Rogaume, Finite element analysis of heat transfer through timber elements exposed to fire, Engineering Structures, 143, 11-21 (2017)

10. C. Erchinger, A. Frangi, M. Fontana, Fire design of steel-to-timber dowelled connections, Engineering Structures, 32, 580-589 (2010)

11. A. Buchanan, Structural design for fire safety, Wiley, Chichester (2001)

12. EN 1995 1-1 Eurocode 5: Design of timber structures, Part 1-1: General rules and rules for buildings, CEN, Brussels, Belgium, (2004)

13. L. Peng, J. Mehaffey, M. Mohammad, Predicting the fire resistance of wood-steel-wood timber connections, Fire Technology, 47, 1101-1119 (2009)

14. A. Frangi, C. Erchinger, M. Fontana, Experimental fire analysis of steel-to-timber connections using dowels and nails, Fire and Materials, 34, 1-19 (2010)
15. C. Maraveas, K. Miamis, E. Matthaiou, Performance of timber connections exposed to fire, Fire Technology, 51, 1401-1432 (2013)

16. P. Moss, A. Buchanan, M. Fragiacomo, C. Austruy, Experimental testing and analytical prediction of the behavior of timber bolted connections subjected to fire, Fire Technology, 46, 129-148 (2010) 